\title{
MOVIMIENTOS SOCIALES VS. BUROCRACIAS DISCIPLINARIAS: LOS DISCURSOS DE LAS NECESIDADES SOCIALES *
}

NANCY FRASER

NORTHWESTERN UNIVERSTYY

Habria muchas maneras de capturar aquello que es distintivo de las sociedades capitalistas tardías con un estado benefactor, en oposición a las culturas políticas capitalistas occidentales de la modernidad temprana. Habria que advertir ahora la mayor actividad del Estado para regular, y en algunas instancias incluso sustituir, los mecanismos de mercado de un sistema económico autónomo. Tendríamos que destacar el crecimiento espectacular del sector de servicios de la economía y el descenso relativo de la manufactura, así como la domesticación, si no es que la franca eliminación del conflicto de clases tradicional y el surgimiento de nuevos agentes sociales organizados colectivamente, tales como las mujeres, la gente de color y los homosexuales. Finalmente podría notarse, incluso, la creciente significación política de las representaciones e imágenes simbólicas, así como las transformaciones en el carácter y papel desempeñado por los medios de comunicación.

Todos estos factores son cruciales para comprender la especificidad de la cultura política contemporánea del capitalismo tardío. Pero ninguno de ellos puede entenderse adecuadamente desde una perspectiva exclusivamente estructural o funcional. Por el contrario, su significación e interrelaciones plenas sólo aparecen cuando las consideraciones estructurales y funcionales se relacionan con otras de carácter discursivo y hermenéutico - como, por ejemplo, cuando los cambios en la estructura social se contextualizan con respecto a los cambios en el carácter del discurso social.

Considérese, entonces, que el discurso político en las sociedades con un estado benefactor es en gran medida un discusro sobre necesidades humanas. Por ejemplo, en los Estados Unidos discutimos si el gobierno debe o no ocuparse de, digamos, la salud pública, y discutimos la rela-

- (C) Center for Humanistic Studies, University of Minnesota, 1986. Se reproduce con autorización. 
ción entre el gasto armamentista y la no satisfacción de tales o cuales necesidades. Por otra parte, en países que cuentan con sistemas de bienestar social más amplios, se discute si los servicios organizados por el gobierno realmente satisfacen las necesidades que pretenden resolver y la manera en que se definen o interpretan tales necesidades. Pese a estas diferencias, en todas las sociedades occidentales con un estado benefactor, hablar sobre las necesidades es un elemento importante en el discurso político. Sin llegar a borrarlos o desplazarlos, se sobrepone a los elementos políticos occidentales más antiguos relacionados con derechos e intereses. De hecho, esta peculiar articulación de un discurso de necesidades con discursos de derechos e intereses constituye la especificidad única de la cultura política de un estado benefactor.

Hablar de necesidades no siempre ha sido central dentro de la cultura política occidental. Por el contrario, en el contexto glorificado del origen de la política occidental, la Atenas clásica, se consideraba antitético hablar de necesidades y de política. Aristóteles definió la polis como una esfera de discurso en la que se deliberaba entre iguales sobre la justicia, los fines y la vida buena; hizo que su "politicidad" excluyera a las necesidades, puesto que éstas eran asunto de esclavos y mujeres confinados al oikos pre-político u hogar, y sólo podia hacerse referencia a ellas en el modo anti-político de la orden del amo. ${ }^{1}$ De manera semejante, en el periodo moderno temprano, con la emergencia de una esfera de producción asalariada separada tanto del hogar como del Estado, "el sistema-de necesidades", como lo llamó Hegel, se alojó dentro de un sistema económico (oficial) relativamente autónomo, excluido de la vida política. ${ }^{2}$ Incluso, cuando se cuestionaron estas divisiones en la última mitad del siglo xIx y principios del xx, la mayor parte de la protesta se refirió a expresiones de derechos e intereses y sólo de manera secundaria a expresiones sobre necesidades. Así el habla sobre las necesidades sólo recientemente ha adquirido importancia como vocabulario dentro del discurso político, en las sociedades occidentales, mientras que ha estado por completo ausente en otras sociedades.

¿Cómo podemos explicar la emergencia relativamente reciente de esta habla sobre necesidades como una expresión central dentro del discurso político en las sociedades capitalistas benefactoras? ¿Cuál es la significación de este desarrollo? ¿Cómo se articula el nuevo discurso de las necesidades con los ya venerables discursos sobre derechos e intereses? ¿Cómo se estructura en esta configuración discursiva particular el cuestionamiento político en las sociedades con un Estado benefactor? ¿Qué

1 Aristóteles, Politics, Libro I.

2 G. W. F. Hegel, The Philosophy of Right, traducción de T. M. Knox (Oxford University Press, 1973), párrafos 189 ss. 
oportunidades y/o limitaciones plantea para los movimientos de oposición interesados en la transformación social?

Se podrían contar distintas historias en relación con el surgimiento de esta habla sobre necesidades. Una de ellas sería la del descenso o perversión de la cultura y el discurso políticos. Se trata del tipo de historia que contaría Hannah Arendt, una de las primeras observadoras de la sociedad capitalista tardía que advirtió la novedad del surgimiento de esta habla sobre necesidades. En pocas palabras, Arendt argumentaba que las sociedades modernas tendian a esfumar la distinción entre lo público y lo privado generando una nueva zona hibrida, intermedia, que llamó "lo social". Lo social, de acuerdo con su definición, es la esfera en la que necesidades hasta entonces privadas, surgen a la vista pública. Estas necesidades irrumpen en la escena pública y se convierten en el objeto de lo que se considera política en las sociedades modernas. Sin embargo, en la perspectiva de Arendt, hacer públicas las necesidades no correspondería tanto al florecimiento de la polf́tica como al ascenso de la administración. Hablar sobre metas da lugar a una obsesión con la "administración doméstica nacional" y esto significa la muerte de la política auténtica. ${ }^{3}$

La explicación de Arendt no carece de interés, e incluso de verdad, en efecto, el surgimiento de esta habla sobre necesidades es un elemento importante dentro del discurso público contemporáneo. En primer lugar, tiene ciertamente razón al relacionar este desarrollo con un cambio en las fronteras entre lo público y lo privado así como al destacar el surgimiento de una zona intermedia a la que llama adecuadamente "lo social". Más aún, tiene también razón al identificar el tenor administrativo de gran parte de esta habla sobre necesidades en las sociedades con un Estado benefactor. Finalmente, su juicio negativo sobre estos cambios puede ser una evaluación apropiada al menos en lo que se refiere a la tendencia hegemónica de la cultura política dentro de dichas sociedades.

Sin embargo, en la explicación de Arendt también hay mucho de improbable e ideológico. Esta autora pretende más que describir y evaluar desarrollos contingentes e históricos, descubrir una dinámica necesaria inherente al surgimiento de esta habla sobre necesidades en cuanto

3 Hannah Arendt, The Human Condition (Chicago: The University of Chicago Press, 1958), especialmente el Capítulo II, pp. 22-78. 
tal. Así, desde su punto de vista, no es casual el triunfo de la administración sobre la política dentro de las sociedades con un Estado benefactor. Más bien, es una consecuencia necesaria del desleimiento de la distinción público-privado y del nuevo carácter público de las necesidades. Para Arendt simplemente no puede haber un discurso político auténtico sobre las necesidades. Por el contrario, el único prospecto para recobrar un discurso político auténtico reside en restaurar la división anterior entre lo público y lo privado y en reprivatizar y deslingüistificar las necesidades humanas.

Varias de las premisas del razonamiento de Arendt son poco probables e ideológicas. Una de ellas es el supuesto de que sólo las sociedades que institucionalizan una separación tajante entre la vida pública y la privada son plenamente adecuadas a "la condición humana". Otra es el supuesto de que las necesidades humanas son en esencia privadas, que son cosas naturales, dadas simplemente, de compulsión bruta, que no están medidas ni construidas por un discurso y por tanto, no pueden incluirse dentro de discursos públicos orientados hacia valores o fines. Son estas concepciones naturalistas y esencialistas de lo privado, lo público y las necesidades, las que conducen a Arendt a clausurar a priori la posibilidad de un discurso polftico público en relación con las necesidades que no esté dominado por una racionalidad administrativa o instrumental. Por ende dichos supuestos la llevan a descartar a priori la posibilidad de una transformación emancipatoria de la cultura politica en un Estado benefactor.

Estas dificultades en la versión de Arendt sobre el surgimiento de esta habla sobre necesidades, nos obligan a buscar una narración diferente. Uno podría narrar el surgimiento del habla sobre necesidades como un progreso, como el descubrimiento de una dimensión legítima de la política que antes habia sido soslayada. En esta historia, las necesidades serían, de hecho, intrínsecamente políticas. De manera que las culturas o sociedades que no las hubieran tratado como tales se habrian equivocado en cuanto a su naturaleza real. Tales sociedades habrían restringido indebidamente el ámbito de la política; excluyendo cuestiones tales como la salud pública, y la necesidad de bienestar, del dominio de lo político. Las sociedades con un Estado benefactor, por otra parte, habrian reconocido el carácter inherentemente político de tales cuestiones. Ampliando en consecuencia, los lfmites de la injerencia estatal permisible y legítima y expandiendo el rango de los problemas que competen a la consideración de la justicia. Así, el surgimiento del Estado benefactor podría ser visto como un avance importante con respecto a organizaciones sociales anteriores, ya que institucionaliza la comprensión 
de las necesidades y de la política que corresponde a la naturaleza intrínseca de las mismas. ${ }^{4}$

Existen buenas razones para preferir esta historia. Para empezar, nota correctamente que el advenimiento del habla sobre necesidades ha significado una ampliación de la comprensión de aquello que cuenta como político dentro de las sociedades capitalistas occidentales. Además, reconoce que esto a su vez significa una extensión del rango de cuestiones que pueden volverse sujetos de las consideraciones de la justicia. Finalmente, la historia como progreso debe atraer simpatías al colocar estos desarrollos bajo una luz positiva; ¿quién podría oponerse, en principio, a la ampliación de las consideraciones de la justicia a cuestiones que involucran las necesidades de la gente?

Por otro lado, la historia como progreso tiene, asimismo, aspectos poco probables e ideológicos. Es unilateralmente optimista, y auto-complaciente. Iguala, de manera no crítica, la ampliación de la política y la justicia con el crecimiento del Estado y al hacerlo soslaya la dimensión administrativa del habla sobre necesidades advertido por Hannah Arendt. Además, la historia como progreso basa también sus premisas en concepciones esencialistas de las necesidades y la política. Supone que la comprensión hegemónica del capitalismo tardio de estas cuestiones corresponde a su naturaleza intrínseca. En consecuencia, la historia como progreso es etnocéntrica. Se despreocupa con ligereza de los pro blemas que surgen cuando tales concepciones se aplican a sociedades con comprensiones culturales y formas de organización muy distintas.

Resulta interesante observar que la historia como progreso comparte algunas características con la historia como decadencia de Arendt. Ambas historias suponen que el status político o no político de la categoria de necesidad es una cuestión de hecho. La historia de Arendt supone que las necesidades son inherentemente no políticas, mientras que la historia como progreso supone que las necesidades son inherentemente políticas. Así, ambas historias evalúan el desarrollo del habla sobre necesidades en términos de un modelo de correspondencia. La historia de Arendt evalúa este desarrollo negativamente porque no logra corresponder con el carácter presente (no político) de la necesidad. La historia del progreso, por otro lado, evalúa el surgimiento del habla sobre necesidades de manera positiva, porque logra, finalmente, corresponder

4 Este tipo de historia del progreso se asocia de manera más prominente con una tendencia del liberalismo post-laissez-faire, social-democrático. Sin embargo, elementos de él se encuentran también en algunas variedades de marxismo occidental, especialmente los marxismos "humanista" y/o "hegeliano" que se basan en la antropología filosófica del "joven Marx" y en algunos autores asociados con la escuela de Frankfurt. Véase Kate Stoper, On Human Needs: Open and Closed Theories in a Marxist Perspective (Atlantic Highlands, NJ: Humanities Press, 1981). 
con el carácter presente (político) de la necesidad. Finalmente, y de manera más fundamental, ambas historias tratan a la categoria de necesidad como una "clase natural"; suponen que alguna versión de la distinción discursiva entre necesidad y no necesidad llegará a la médula de la realidad, independientemente de la manera en que cualquier cultura dada tematice la necesidad en un discurso.

Desde luego, existe la posibilidad de otro tipo de historia en relación con el surgimiento del habla sobre necesidades en el capitalismo benefactor, una historia que no depende de los supuestos compartidos por las historias de la decadencia y el progreso. Este tercer tipo de historia es el que asociamos con Michel Foucault. Una historia foucaultiana no supondrfa que hay una versión de la distinción discursiva entre necesidades y no necesidades que llega a la médula de la realidad y que luego toca a diversas culturas llegar o no a descubrir. Esta historia no intentaría evaluar los méritos relativos de las culturas con y sin esta habla sobre necesidades en términos de lograr o no corresponder con la estructura ontológico-categorial de la propia realidad tal y como es en si misma, independientemente de cualquier vocabulario que se use para describirla. Más aún, una historia foucaultiana sobre el ascenso del habla sobre necesidades no supondria que hay hecho alguno en cuanto al carácter inherentemente político o no político de las necesidades humanas. Así, no intentaría evaluar los méritos relativos de culturas con o sin esta habla sobre necesidades politizada, en términos de la correspondencia de éstas con la verdadera naturaleza de las necesidades, independientemente de cualquier vocabulario humano que se use para describirlas. Por el contrario, una historia foucaultiana narraría el surgimiento del habla sobre necesidades como la invención o creación de un nuevo vocabulario político. ${ }^{5}$

Esto no quiere decir que una histiria foucaultiana fuera incapaz de plantear puntos evaluativos. Ni que, en la medida en que lo hiciera, se le pidiera hacer evaluaciones exclusivamente negativas. Desde luego, es cierto que el propio Foucault algunas veces afirmó que su enfoque era puramente descriptivo y no evaluativo. Es también cierto que usual-

5 El propio Foucault no escribió una historia foucaultiana del habla sobre necesidades per se. Sin embargo, sf́ escribió historias del tipo que describo acerca del habla sobre derechos, sexo y lo que podría denominarse el ser o si mismo profundo. Además, las explicaciones de Foucault del desarrollo del "bio-poder", la "mentalidad gubernamental" y la "ciencia social disciplinaria" tocan muchos puntos que podrían estar relacionados con una historia foucaultiana sobre el desarrollo del habla sobre necesidades. Véase Foucault, Discipline and Punish: The Birth of the Prison, traduccion de Alan Sheridan (New York: Vintage, 1979); The History of Sexuality, vol. I, An Introduction, traducción de Robert Hurley (New York: Pantheon Books, 1978); y Power/Knowledge: Selected Interviews and Other Writings 1972-1977, editado por Colin Gordon (New York: Pantheon Books, 1980). 
mente su retórica estaba cargada de valoraciones negativas acerca de los cambios en el vocabulario que apuntaba, y que algunas veces tendía a igualar el carácter inventivo de la creación de vocabulario con una "mera ficcionalización" en sentido peyorativo. ${ }^{6}$ Pero estas peculiaridades del discurso del propio Foucault no son esenciales para el método foucaultiano. Por el contrario, una historia foucaultiana sobre el surgimiento del discurso de necesidades en la cultura política del capitalismo tardío evaluaría estos acontecimientos y lo podría hacer, en principio, tanto negativa como positivamente. Lo que no podría hacer es etiquetar dichas evaluaciones como cuestiones de correspondencia. Más bien, tendría que considerarlas como cuestiones pragmático-políticas, como juicios sobre las diversas utilidades del habla sobre necesidades con respecto a diversos propósitos políticos. Por ejemplo, podría evaluar las diversas tendencias del habla contemporánea sobre las necesidades en términos de su capacidad para promover o inhibir la realización de valores políticos establecidos independientemente, tales como la igualdad, la adquisición de poder por parte de nuevos sujetos políticos y la participación democrática.

\section{III}

Si uno quisiera contar una historia cuasi-foucaultiana sobre el desarrollo del habla sobre necesidades, sería menester desarrollar una concepción profundamente cultural e historizada de la necesidad. Además, habría que especificar la relación entre esta concepción de necesidad y el discurso social.

Supongamos que se comienza por introducir la idea de "los medios socio-culturales de interpretación y comunicación". Por medios socioculturales de interpretación y comunicación (MIC) me refiero al conjunto histórica y culturalmente específico de recursos discursivos disponibles para los miembros de una colectividad social dada. Entre estos recursos se encuentran:

1. Las expresiones coloquiales reconocidas oficialmente que se usan para presentar demandas; por ejemplo, en nuestra sociedad, hablar de necesidades, de derechos, o de intereses.

2. Los vocabularios disponibles para instanciar demandas en estas ex-

6 Para discusiones criticas de estas caracteristicas del trabajo de Foucault, véase Nancy Fraser, "Foucault on Modern Power: Empirical Insights and Normative Confusions", Praxis International, vol. I, núm. 3 (octubre de 1981), pp. 272-287; "Foucault's Body Language: A Post-Humanist Political Rhetoric?" Salmagundi, núm. 61 (otoño 1983), pp. 55-70; y “Michel Foucault: A 'Young Conservative"?" Ethics, 96 (octubre de 1985), pp. 165-184. 
presiones reconocidas; por ejemplo, donde hablar de necesidades es una expresión reconocida, ¿cuáles serían los vocabularios disponibles para interpretar y comunicar las necesidades de una persona?

3. Los paradigmas de argumentación aceptados como autorizados para dirimir demandas en conflicto; por ejemplo, en esta habla sobre necesidades, ¿cómo se resuelven los conflictos referidos a la interpretación de necesidades?

4. Las convenciones narrativas disponibles para construir las historias individuales y colectivas que son constitutivas de la identidad social, por ejemplo, las épicas, trágicas, románticas, dialécticas, psicoanalíticas, etc., como convenciones que determinan lo que cuenta como una historia posible e inteligible y en consecuencia lo que es narrable.

5. Modos de objetivación y personificación; las maneras en que diversos discursos constituyen sus referentes respectivos como tipos especificos de objetos; las diversas maneras o formas de dirigirse a sujetos y a sus posiciones como tipos específicos de personas con capacidades específicas para la acción.

6. El repertorio de recursos retóricos disponibles.

7. Las dimensiones corporales y gestuales del habla que se asocian en una cultura dada por ejemplo, con la autoridad y la convicción, o en su caso, con la falta de autoridad y convicción.?

Probablemente esta lista no sea exhaustiva, pero bastaría para indicar algunas de las maneras en que el habla referida a necesidades en general y el habla sobre necesidades específicas están mediadas cultural e históricamen'te. Sugiere, por ejemplo, que una condición para que sea posible hablar de necesidades es que los medios de interpretación y comunicación de la colectividad social sean de un tipo específico. Esto a su vez sugiere que no es especialmente útil concebir a los poseedores de necesidades primordialmente como seres biológicos. Más bien, los poseedores de necesidades tendrian que verse como miembros de colectividades de discursos. Esto es, como sujetos encarnados que son tanto protagonistas de historias de vidas regidas por convenciones como personas interpeladas por formas particulares de interpelación que les atribuyen capacidades específicas para la acción. Además, las necesidades que demandan estos sujetos o les son atribuidas, pueden comprenderse mejor si se ven como un momento interpretativo irreductible o hermenéutico, de ahí que estén sujetas a la interpretación y potencialmente, conflictos de interpretación.

Esta concepción discursiva, cultural-histórica de la necesidad puede

7 Para otra explicación de esta idea de los medios socio-culturales de interpretación y comunicación véase Nancy Fraser, "Towards a Discourse Ethic of Solidarity", Praxis International, vol. 5, núm. 4 (enero de 1986), pp. 425-429. 
refinarse aún más si tomamos en cuenta el carácter complejo y diferenciado de muchas colectividades sociales. Ciertamente, las sociedades capitalistas occidentales modernas en donde hablar de necesidades ha llegado a ocupar un lugar prominente, comprenden una pluralidad de formas de asociación, roles, grupos, instituciones y discursos. $Y$ por ende, en estas sociedades los medios de interpretación y comunicación no forman un todo cerrado. No son una red coherente y monolítica sino más bien un campo heterogéneo y políglota en donde elementos discursivos diversos coexisten algunas veces de manera tensa y difícil. Así, la noción bakhtiniana de una heteroglosia dialógica es más apta como una descripción de los MIC en sociedades complejas que la idea lacaniana de Lo Simbólico o la idea saussuriana de un código sin fracturas. Más aún, cuando éste es el caso, cuando 'os MIC son heterogéneos y potencialmente conflictivos, los discursos sobre las necesidades tienden a hacer referencias, por lo menos implícitas, a una pluralidad de posibles interpretaciones. Las demandas particulares sobre necesidades están "dialogizadas internamente" en la medida en que tienden implícita o explícitamente a evocar resonancias de interpretaciones alternativas de necesidades y con ello a la posibilidad de un conflicto en la interpretación de las necesidades. ${ }^{8}$

Por otra parte, es importante notar que las sociedades en donde hablar de necesidades se ha vuelto prominente, como tantas otras sociedades, no son simplemente pluralistas. Más bien, son sociedades estratificadas, que comprenden grupos con desigual status, poder y acceso a

8 Al pretender que las concepciones bakhtinianas de heteroglosia y dialogización son especialmente aptas con respecto a sociedades complejas y diferenciadas, incluyendo las sociedades del capitalismo tardio con un estado benefactor, estoy rompiendo intencionalmente con la posición del propio Bakhtin. El suponía, por el contrario, que estas concepciones encontraban su expresión más robusta en la cultura "carnavalesca" de la Europa medieval tardía y que la historia subsecuente de las sociedades occidentales conllevó un achatamiento del lenguaje y una restricción de la heteroglosia dialógica al dominio esotérico y especializado de "lo literario". Esto parece ser patentemente falso - especialmente cuando reconocemos que el carácter dialógico y contestatario del habla se relaciona con la disponibilidad en una cultura de una pluralidad de discursos en competencia y de posiciones de los sujetos a partir de las cuales se les articula. Asi, conceptualmente, uno podría esperar lo que, supongo, es el caso: que el habla en las sociedades complejas y diferenciadas sería especialmente adecuada para un análisis en términos de estas categorías bakhtinianas. Para las concepciones bakhtinianas de heteroglosia y dialogización interna véase "Discourse in the Novel", en The Dialogical Imagination: Four Essays by M. M. Bakhtin, traducción de Caryl Emerson y Michael Holquist (Austin, Texas: University of Texas Press, 1981), pp. 259-422. Para una segunda explicación útil véase Dominick LaCapra, "Bakhtin, Marxism and the Carnivalesque", en Rethinking Intellectual History (Ithaca, N. Y.: Cornell University Press, 1983), pp. 294-324. Para una crítica del sesgo romántico, anti-modernista tanto en Bakhtin como en LaCapra, véase Nancy Fraser, "On the Political and the Symbolic: Against the Metaphysics of Textuality", Boundary 2 (en prensa). 
los recursos. Estas sociedades, en otras palabras, están atravesadas por profundos ejes de dominación y subordinación a través de líneas de clase, género, raza, etnicidad y edad. Más aún, los MIC en estas sociedades están estratificados ellos mismos; se organizan e institucionalizan de maneras que son congruentes con patrones sociales de dominación y subordinación y portan las marcas de estas desigualdades estructurales. Así, por un lado, podemos distinguir aquellos elementos de los MIC que son hegemónicos, que están sancionados y autorizados oficialmente, de aquellos que no son hegemónicos, y son descalificados o ignorados por el otro. Por ejemplo, algunas expresiones, vocabularios, paradigmas de argumentación, convenciones narrativas, modos de objetivación y personificación, recursos retóricos y gestos corporales, están enraizados en las arenas discursivas centrales de la sociedad capitalista tardía, y son institucionalizados en parlamentos, academias, cortes y medios masivos de circulación. Mientras que otras expresiones, vocabularios, etc., están enclavados como sociolectos subculturales y están excluidos en gran medida de estas arenas discursivas centrales. Más aún, cuando estos modos no hegemónicos llegan a incidir en el centro discursivo, tienden a ser representados como marginales o anómalos.

Asi, en las sociedades capitalistas benefactoras, las demandas encerradas en las expresiones de necesidades están dialogizadas internamente y tienden a evocar contrademandas conflictivas. Por otro lado, este dialogismo actúa como foco o medio de un cuestionamiento que tiene lugar dentro de los ejes de dominación y subordinación existentes. Es ahí donde los grupos con recursos discursivos (y no discursivos) desiguales luchan por establecer como hegemónicas sus respectivas interpretaciones de necesidades sociales legítimas. Por ejemplo, los grupos dominantes articulan interpretaciones de necesidades con la esperanza de que se excluyan, diluyan y/o coopten posibles contrainterpretaciones. Los grupos subordinados o de oposición, por otro lado, artculan interpretaciones dé necesidades que buscan cuestionar, desplazar y/o modificar las interpretaciones dominantes. En ambos casos, estos actos interpretativos constituyen intervenciones. $\mathrm{Y}$ es a partir de este intercambio contestatario entre las interpretaciones en competencia que surgen interpretaciones hegemónicas de necesidades como aparentemente estables y autorizadas. ${ }^{9}$ Por otra parte, las subjetividades se cristalizan y recristalizan en torno a formas alternativas de interpretación que compiten por la anticuación de las demandas de necesidades.

9 Para el uso de una perspectiva teórica similar en un contexto distinto véase $T$. J. Clarke, "Beliefs and Purposes in David's Death of Marat, Seminario 2 (manuscrito inédito). 
Lo dicho anteriormente debería bastar para poner en duda la concepción usual, de sentido común, del proceso mediante el cual las necesidades se vuelven la base de demandas políticas en las sociedades capitalistas con un Estado benefactor. En términos generales, esta concepción consiste en que cuando las necesidades no se satisfacen de una manera tangible y se experimentan como tales, dan lugar a demandas públicas de satisfacción, usualmente demandas al Estado. El carácter inadecuado de esta concepción es evidente cuando consideramos que deja fuera dimensiones importantes de la política del habla sobre necesidades. En primer lugar, se ocupa del carácter de las necesidades en cuestión y por tanto de lo que cuenta como su satisfacción, simplemente como algo dado y no problemático; así oscurece la dimensión interpretativa del proceso, esto es, el hecho de que no sólo las necesidades sino las interpretaciones de las necesidades son a menudo las que están en discusión. En segundo lugar, la concepción del sentido común da por sentado que no es un problema el considerar quién interpreta las necesidades en cuestión, así como la perspectiva desde la cual lo realiza y la relación que tenga con intereses determinados. De ese modo, se oculta el hecho de que el problema de quién define las necesidades es a menudo, en sí mismo, una cuestión política. En tercer lugar, la concepción del sentido común da por hecho el carácter adecuado y justo de los recursos discursivos autorizados y disponibles para interpretar las necesidades en cuestión; así oculta la pregunta de si los elementos hegemónicos de los medios de interpretación y comunicación son capaces de dar voz a las necesidades experimentadas por grupos subordinados o de oposición o si, más bien, expresan la experiencia, auto-interpretaciones e intereses de grupos dominantes; ocultando, con otras palabras, el hecho de que el carácter y organización de los propios MIC puede ser una cuestión política. ${ }^{10}$ En cuarto lugar, esta concepción no enfoca la lógica social e institucional de los procesos de la interpretación de las necesidades y esconde el carácter político de cuestiones tales como: ¿cuál es el lugar o sitio institucional donde se desarrollan las interpretaciones autorizadas de las necesidades? y ¿cuál es el carácter de las relaciones de comunicación entre los intérpretes? Por tanto, hay al menos cuatro dimensiones políticas importantes que se ocultan en la posición del sentido común en esta cuestión.

Un mejor modelo para ver la manera en que las necesidades se vuelven puntos de lucha política permite tres momentos analíticamente dis-

10 Para una discusión más completa de este punto véase Nancy Fraser, "Towards a Discourse Ethic of Solidarity", op. cit. 
tintos pero interrelacionados prácticamente. El primero es el momento de lucha para establecer o negar el status político de una necesidad dada, la lucha para validar la necesidad como una cuestión de legítima preocupación pública o para enclavarla como una cuestión privada. Al segundo momento lo constituye la lucha por la interpretación de la necesidad como lucha por el poder para definirla y así determinar qué podría satisfacerla. El tercer momento es el de la lucha por la satisfacción de la necesidad.

Es claro que la lucha para establecer o negar el status político de una necesidad dada incluye la cuestión de lo privado frente a lo público, dado que en los contextos de Estados benefactores es pertinente para quienes buscan legitimar una cuestión de necesidades como política, plantear el asunto como público y no como una cuestión meramente privada. Desde luego, los propios términos 'privado' y 'público' son objeto de cuestionamientos y tienen sentidos diferentes. En el contexto presente, los dos sentidos más importantes son los siguientes: el primero, es lo que llamaré "el sentido del discurso" en donde 'privado' quiere decir a salvo de, y 'público' quiere decir sujeto a argumentos y discursos colectivos. El segundo es lo que llamaré "el sentido del estado", donde 'privado' significa a salvo de, y 'público' quiere decir sujeto a una intervención estatal legítima. Estos dos sentidos están relacionados. Usualmente, una condición para que una cuestión sea pública en el sentido del estado es el que sea pública en el sentido del discurso; esto es, usualmente una necesidad no se vuelve sujeta a la intervención estatal legitima sino hasta que ya ha sido sujeta al discurso o argumentos colectivos.

Vale la pena notar que la frontera entre lo público y lo privado en el sentido del discurso está constituida cultural e históricamente. No parece haber limitaciones a priori que dicten que algunas cuéstiones sean simple o intrínsecamente privadas en este sentido y otras simple o intrínsecamente públicas. De hecho, la frontera se establece de manera distinta de cultura a cultura y de un periodo histórico a otro. Más aún, la posibilidad misma de establecer límites depende de la existencia de un grado de diferenciación institucional que ofrezca una arena o ám. bito para el discurso y argumento colectivos que sea distinta de los espacios sociales reservados o resguardados de la publicidad. La separación oikos-polis en la Atenas clásica es un ejemplo de una diferenciación institucional tal que permite una frontera entre lo público y lo privado en el sentido del discurso.

Dado el carácter histórico y cultural de la distinción entre lo público y lo privado en el sentido del discurso, ¿cómo debemos conceptualizar la politización de las necesidades en las sociedades capitalistas benefac- 
toras? En estas sociedades, tanto el surgimiento del habla sobre necesidades en la política en general como la politización de ciertas necesidades específicas incluyen procesos mediante los cuales algunas necesidades rompen las envolturas de lo privado discursivo que previamente las contenían y se vuelven focos de un discurso público contestatario. El carácter de estas necesidades —sus interpretaciones_ y el carácter del discurso contestatario que las rodea _el conflicto de las interpretaciones de las necesidades - están estructurados en parte por estos procesos. Los discursos políticos sobre las necesidades en las sociedades capitalistas benefactoras conservan las huellas de su prehistoria; están marcadas por el hecho de haber estado resguardadas del discurso y muestran asimismo las marcas de su ruptura e irrupción en lo público.

\section{V}

¿Cuáles son las envolturas de lo privado que previamente contenian necesidades recientemente politizadas en las sociedades capitalista benefactoras que dejaron su marca en estas necesidades? ¿Cuáles son las instituciones en donde se enclavaban estas necesidades y se separaban de los espacios institucionalizados del discurso público colectivo, en donde sus interpretaciones se naturalizaban, reificaban y circunscribían?

En las sociedades occidentales modernas, hay dos instituciones principales que han operado para privatizar las necesidades. Son las instituciones domésticas, especialmente la forma doméstica normativa, a saber, la familia nuclear moderna, restringida, con un jefe de familia masculino y las instituciones oficiales del sistema económico capitalista, especialmente los lugares de trabajo asalariado, mercados, sistemas de crédito y empresas. ${ }^{11}$ Las instituciones domésticas privatizan las necesidades al personalizar y/o familiarizarlas; las necesidades en cuestión se consideran cuestiones privadas domésticas o personal-familiares, a diferencia de las cuestiones públicas y políticas. Las instituciones económicas oficiales del sistema capitalista, por otra parte, privatizan las necesidades al economizarlas; las necesidades en cuestión se consideran aquí como cuestiones económicas de mercado o empresariales y no como cuestiones públicas, políticas.

Es claro que las instituciones domésticas y del sistema económico

11 A través de este artículo me refiero a lugares de trabajo asalariado, mercados, sistemas de crédito, etc., como "instituciones del sistema económico oficial" de manera que se evite la implicación androcéntrica de que las instituciones domésticas no son también "económicas". Para una discusión de este problema véase Nancy Fraser, "What's Critical About Critical Theory? The Case of Habermas and Gender", New German Critique 35 (primavera/verano de 1985), pp. 97-131. 
oficial difieren en varios sentidos importantes. Sin embargo, en este sentido, esto es, con respecto a la privatización o despolitización de las necesidades, están exactamente una a la par de la otra. Ambas separan ciertas cuestiones del discurso público colectivo; ambas apartan tales cuestiones del cuestionamiento abierto y conflictos interpretativos abiertos; y ambas atrincheran dentro de la autoridad ciertas interpretaciones especificas de estas cuestiones, si bien otorgándoles una apariencia de naturalidad y facticidad.

Más aún, dado que tanto las instituciones domésticas como las del sistema económico oficial instancian relaciones de dominación y subordinación, las interpretaciones especificas que naturalizan tienden generalmente a favorecer a los grupos e individuos dominantes y a crear situaciones de desventaja para sus subordinados. Si la agresión doméstica, por ejemplo, está enclavada como una cuestión privada dentro de las instituciones domésticas y protegida del discurso público, ello sirve para reproducir la dominación sexual y la subordinación dentro de estas instituciones y en la sociedad en su conjunto. De manera semejante, si la salud ocupacional y las cuestiones de seguridad se enclavan como cuestiones privadas en lugares de trabajo con una orientación hacia las ganancias y una administración jerárquica, ello sirve para reproducir la dominación y subordinación de clase (y a menudo sexual y racial) dentro de estas instituciones y en la sociedad en su conjunto.

La economía familiar y oficial constituyen así las principales envolturas de lo privado a través de las cuales las necesidades deben irrumpir para convertirse en públicas en el sentido del discurso en las sociedades capitalistas benefactoras. Así, el surgimiento de esta habla sobre necesidades como una expresión política dentro de estas sociedades es en efecto el otro lado del fracaso de las instituciones domésticas y económicas oficiales para continuar considerando ciertas cuestiones como privadas. En muchos (aunque no sea en todos) los casos, estos fracasos de contención involucran la cristalización de subjetividades nuevas, de oposición, tanto por parte de personas como de grupos subordinados. Esto es, las necesidades se politizan cuando, por ejemplo, mujeres, trabajadores, gente de color, etc., empiezan a cuestionar sus identidades y papeles subordinados, y las interpretaciones de necesidades tradicionales, reificadas y desventajosas asignadas previamente a, o adoptadas por ellos, dentro de instituciones domésticas y económicas oficiales. El habla sobre necesidades en la política, entonces, a menudo es introducida por personas y grupos subordinados dentro del proceso de conformar identidades sociales nuevas, de oposición social. 
Al insistir en hablar públicamente de necesidades privadas hasta ese momento, al demandar para estas necesidades el status de cuestiones políticas legítimas, tales personas y grupos hacen varias cosas simultáneamente. Cuestionan los límites instituidos que separan lo público de lo privado; ofrecen interpretaciones de sus necesidades que se contraponen a interpretaciones enraizadas, reificadas y privatizadas; y de manera más o menos exitosa, abren un espacio para el conflicto abierto de interpretaciones rivales de necesidades. Además, tales grupos y personas pueden inventar nuevos vocabularios para la interpretación de necesidades o pueden retar, modificar y/o desplazar los vocabularios existentes. De manera más general, pueden cuestionar, modificar y desplazar o suplementar un rango mayor o menor de componentes de los medios socialmente reconocidos e instituidos de interpretación y comunicación. Pueden rechazar como inadecuados varios elementos hegemónicos de los MIC y buscar la rehabilitación o revaluación de elementos marginales, no hegemónicos; o pueden buscar introducir nuevos recursos discursivos.

En la medida en que se adoptan nuevas necesidades o necesidades interpretadas de una nueva forma, en la medida en que se adoptan nuevas convenciones narrativas para relatar historias nuevas o modificadas de sus vidas y en la medida en que se instituyen nuevas formas de interpretación o personificación o que las modifican, las personas y grupos subordinados comprometidos con el habla sobre necesidades, reformulan sus propias subjetividades e identidades sociales. Se interpelan a sí mismos y a otros como diferentes tipos de personas, a menudo de maneras que tienden $o$ intentan promover nuevas identificaciones colectivas. Asf, hablar de necesidades a menudo es un momento en la auto-constitución de nuevos agentes colectivos o movimientos sociales. Por ejemplo, en la ola actual de fermentación feminista, las mujeres -hasta ahora una identificación social pre o no política sobrecargada de significados tradicionales de roles sexuales bajo el disfraz de lo 'dado'- han politizado y reinterpretado varias necesidades instituyendo nuevos vocabularios y formas de interpelación, y al hacerlo se han vuelto mujeres en un sentido diferente, si bien no incuestionable ni univoco. Al hablar públicamente de lo hasta entonces inmencionable, al acuñar términos como 'sexismo', 'hostigamiento sexual', 'violación marital, de novios y conocidos', 'segregación sexual de la fuerza de trabajo', 'la doble jornada', 'agresión a esposas', etc., las mujeres se han vuelto mujeres en el sentido de una colectividad constituida, aunque se trate de una comunidad muy heterogénea y fracturada. 
La politización de las necesidades y el habla sobre necesidades, tal y como la emplean los agentes y colectividades de oposición, no permanece, desde luego, sin cuestionamientos. Por el contrario, los propulsores de la desprivatización de las necesidades se enfrentan a la oposición de una variedad de sectores. Un tipo de oposición proviene de quienes defenderfan lo que puede llamarse la división social establecida de discursos. Tales agentes pueden insistir, por ejemplo, en que la agresión doméstica no es un tema legítimo de discurso público sino una cuestión privada y familiar. O, para tomar un ejemplo distinto, que el cierre de una fábrica es una cuestión económica privada y no una cuestión pú- blica y política. En ambos casos, los agentes en cuestión defiendo fronteras establecidas entre lo público y lo privado y la integridad de viejos juegos de lenguaje institucionalmente anclados. Cuestionan el escape de necesidades prófugas y buscan su reprivatización. En casos en los que, desde su perspectiva, las cosas han ido demasiado lejos, se encuentran ante la posición paradójica de tener que embarcarse en un discurso público y político con el fin de poner fin a tal discurso. Así, los neoconservadores económicos han hablado recientemente, en público, con gran amplitud, del carácter esencialmente privado de una variedad de necesidades recientemente politizadas. De igual manera, los representantes de la 'mayoría moral' han creado un discurso público y político que tiene como finalidad, en parte, repatriar a sus antiguos enclaves domésticos a las necesidades recientemente politizadas por las feministas.

Estos discursos asimismo portan las marcas de una historia previa. Articulan explícitamente interpretaciones de necesidades que anteriormente podrian pasar de largo. Pero al hacerlo, modifican sutilmente estas interpretaciones de necesidades, dado que se trata de intervenciones en respuesta a interpretaciones rivales, y así se dialogizan internamente con respecto a éstas.

Así, los defensores de la división social establecida entre discursos niegan las demandas hechas por los movimientos sociales para legitimar el status público de las necesidades prófugas. Juntos, estos dos conjuntos de oponentes codefinen un eje de cuestionamiento con respecto al habla sobre necesidades en las sociedades capitalistas benefactoras. Este eje enfrenta movimientos institucionalmente ilimitados a fuerzas contrarias institucionalmente limitadas. Es un eje de lucha cuyo foco principal está constituido por los límites institucionales legítimos de juegos de lenguaje sobre las necesidades, esto es, los límites entre los discursos público y privado. Pero involucra, al mismo tiempo, choques entre interpretaciones rivales de necesidades sociales. 
Hay también un segundo eje, más bien distinto, de cuestionamiento que concierne las necesidades en las sociedades capitalistas benefactoras. Este eje corresponde más o menos con los momentos segundo y tercero de la lucha por las necesidades identificados anteriormente, a saber, las luchas por el poder para definir y satisfacer las necesidades cuestionadas una vez que su status público y político se ha establecido con mayor o menor éxito. Aquí, el punto focal ya no es lo público frente a lo privado en el sentido del discurso, sino más bien el contenido y proceso mismos de la interpretación de la necesidad. $\mathrm{Y}$ aquí, los principales actores son los movimientos sociales de oposición y el Estado.

En las sociedades capitalistas benefactoras, aquellas necesidades que han roto la envoltura de lo privado que anteriormente las contenía, y que han ganado un lugar dentro del discurso público, entran en aquel espacio discursivo híbrido que Arendt llamó adecuadamente "lo social". En este espacio las interpretaciones rivales de las necesidades chocan en tanto que movimientos sociales opuestos. Es también un espacio donde las interpretaciones de las necesidades en competencia, desarrolladas en el contexto de movimientos sociales institucionales abiertos, tienden a traducirse en demandas de satisfacciones organizadas públicamente. En el terreno de lo social, las necesidades que ya son públicas en el sentido del discurso se vuelven candidatas a públicas en el sentido del Estado; se vuelven candidatas para una intervención estatal legítima. Después de ganar un lugar en la agenda política informal buscan un lugar dentro de la agenda formal del sistema político oficial. ${ }^{12}$ Así, en el terreno de lo social, los movimientos de oposición se encuentran en relaciones complejas y frecuentemente tensas con el Estado.

De hecho, el Estado, en sus diversos brazos y ramas, es un actor entre otros en la lucha por las interpretaciones conflictivas de necesidades dentro del espacio de lo social. Este hecho, asimismo, es resultado de una historia previa, a saber, la culminación de una vieja tendencia en las sociedades capitalistas occidentales a incrementar la involucración estatal en la regulación de la reproducción social. En parte como respuesta a inestabilidades económicas y políticas en sociedades capitalistas anteriores, los gobiernos han asumido un papel más activo en la organización de la vida social. Cuestiones que anteriormente se dejaban en manos de las instituciones de funcionamiento semiautónomo del sistema económico oficial e instituciones domésticas patriarcales burguesas han caído crecientemente dentro de la injerencia de una intervención gu-

12 Para una apropiación feminista de la distinción entre la agenda política formal e informal véase Drude Dahlerup, "Overcoming the Barriers: An Approach to the Study of How Women's Issues are Kept from the Political Agenda", en Women's Views of the Political World of Men, editados por Judith Hicks Stiehm (Dobbs Ferry, N. Y.: Transnational Publishers, 1984), pp. 31-66. 
bernamental legítima y positiva. Por ejemplo, los estados en las sociedades capitalistas benefactoras buscan de manera rutinaria desviar o manejar las crisis económicas mediante estrategias de "sustitución de mercados" que dan lugar al ascenso de un "sector público". Igualmente, buscan desviar o manejar crisis sociales y políticas mediante medidas "compensatorias de mercado y/o domésticas" tales como concesiones de bienestar social a sindicatos y movimientos sociales. En ambos casos, el resultado ha sido el desarrollo de nuevas agencias e instituciones dentro del sistema administrativo del Estado. El Estado ha desarrollado de hecho un brazo nuevo; lo podemos llamar el brazo social del Estado. ${ }^{13}$

El estado social es un complejo multiforme y diferenciado de agencias y aparatos. En los Estados Unidos comprende, por ejemplo, el Departamento de Vivienda, Educación y Bienestar (HEW), la Administración de Seguridad Social, Vivienda y Desarrollo Urbano (HUD), la administración Ocupacional y de Seguridad (OSHA), la Agencia de Protección al Medio Ambiente (EPA), la Comisión de Derechos Civiles y el Consejo Nacional de Relaciones Laborales (NLRB) -o lo que actualmente queda de ello. Estas agencias y otras a niveles federal, estatal y local, se ocupan de regular y fundar o satisfacer necesidades sociales antes privatizadas. De manera típica, la organización del Estado social de satisfacción de necesidades adopta la forma de "servicios sociales". El diseño e instrumentación de servicios sociales se ocupa, igualmente, de interpretar, así como de satisfacer necesidades sociales.

Así, cuando los movimientos sociales logran politizar necesidades previamente privatizadas, ingresan al terreno de lo social, donde deben encontrarse con el estado social. Este encuentro, asimismo, incluye conflictos entre interpretaciones rivales de las necesidades sociales. De manera más fundamental, incluye conflictos entre géneros o lógicas sociales rivales de interpretaciones de las necesidades.

\section{VII}

La manera que tiene el Estado social de dirigirse a las necesidades sociales está estructurada por una lógica administrativa de la definición

13 Para una discusión de las actividades del manejo de crisis de los gobiernos del capitalismo tardío, incluyendo la sustitución de mercados y las actividades compensatorias del mercado, véase Jürgen Habermas, Legitimation Crisis, traducción de Thomas McCarthy (Boston: Beacon Press, 1975). Si bien un enfoque de Habermas es útil en muchos sentidos, resulta equivocado en el sentido de que privilegia las tendencias de las crisis que se originan en el sistema económico capitalista oficial y oculta el carácter igualmente primordial de las tendencias de las crisis que se originan en la esfera doméstica burguesa-patriarcal. Para una critica del tratamiento de Habermas 
de las necesidades. De hecho, éste es un género de discursos sobre necesidades entre otros más, un género que Hannah Arendt identificó equivocadamente con el habla sobre necesidades per se. De manera más precisa, se trata de una serie de operaciones de re-escritura, un conjunto de procedimientos mediante los cuales las necesidades politizadas se traducen a necesidades administrables.

El programa del Estado social para reescribir las necesidades politizadas es grosso modo, el siguiente: la necesidad politizada se redefine como un concepto correlativo de una satisfacción burocráticamente administrable, un "servicio social". Ello requiere de criterios claros y objetivos de elegibilidad tales que una agencia organizada burocráticamente pueda determinar quién tiene la necesidad y quién no. Esto, a su vez, significa que la necesidad debe especificarse en términos de un estado de cosas generalizable que podría aplicarse, en principio, a cualquiera - por ejemplo, desempleo, incapacidad, muerte o abandono de cónyuge. La necesidad, en otras palabras, debe descontextualizarse y despojarse de los significados sociales e individuales que adquirió en el movimiento de la privatización a la politización. Como resultado, se reubica al poseedor de la necesidad, y el Estado social lo interpela de una manera simultáneamente individualizadora y generalizadora. El poseedor de la necesidad se reubica como un individuo demandante que debe demostrar que su caso satisface los criterios de elegibilidad, esto es, como una instancia de buena fe del estado de cosas especificado y generalizable. Como solicitante a una agencia autorizada para que decida sobre la demanda con base en procedimientos administrativos, el poseedor no debe asumir la posición de un agente político o miembro de una colectividad constituida.

Más aún, dado que el problema politizado de la vida del demandante debe concordar con una solución administrable burocráticamente, y volverse conmensurable con los términos de tal solución. Esto quiere decir que la necesidad debe cuantificarse y redefinirse como el equivalente en una cantidad de dinero. Esto, asimismo, es una operación descontextualizadora y, por tanto, también reubica al poseedor de la necesidad. ${ }^{14}$ En el sistema de seguridad social estadounidense, de hecho hay dos subvariantes de esta operación, dependiendo de si las satisfacciones de las necesidades se dan en efectivo o en "especie". Esta distinción se correlaciona en gran medida con el género, dado que beneficios "en especie" como de este y otros puntos véase Nancy Fraser, "What's Critical About Critical Theory? The Case of Habermas and Gender", op. cit.

14 La discusión anterior de la lógica administrativa de la definición de necesidades se debe a Jürgen Habermas, Theorie des kommunikativen Handelns, Band II, Zur Kritik der funktionalistischen Vernunft. (Frankfurt am Main: Surkamp Verlag, 1981, pp. 522-547.) 
bonos de comida, ayuda médica (medicaid) y vivienda popular, se relacionan con programas de ayuda con una orientación doméstica, en oposición a programas de seguridad para contribuyentes tales como la Seguridad Social (seguro de jubilación) y el seguro de desempleo. Mientras que los últimos están ligados a la participación en la fuerza de trabajo primaria asalariada y se diseñan para beneficiar a los trabajadores primarios (normativamente masculinos), los primeros están destinados a sectores de ingreso familiar combinado y diseñados para familias (con un jefe de familia ${ }^{*}$ femenino) sin asalariados (masculinos). Así, los participantes en los programas de seguridad social están individualizados como'trabajadores, se les pagan beneficios en efectivo y con ello se les ubica, en última instancia, como consumidores. Las participantes en los programas femeninos de ayuda, por otro lado, se consideran como madres, se les otorgan los beneficios "en especie" y así se les ubica como clientes en el sentido de dependientes. Se establece una diferenciación clara de státus entre los dos tipos de receptores de beneficios. Los receptores-trabajadores-consumidores son interpelados como "individuos poseedores" que reciben los beneficios que merecen como una cuestión de derecho. Los receptores-clientes-madres, por otro, son interpelados como los negativos de individuos poseedores que están "riecibiendo el seguro de desempleo", y son "beneficiarios de la generosidad del gobierno". ${ }^{15}$

Estas diferencias tienen una enorme significación política. Son rastros visibles de la historia de la política de las necesidades en los Estados

15 Para el sistema de seguridad social en los Estados Unidos véase el análisis de las tasas de participación femeninas y masculinas, y la explicación del carácter sexuado de los dos subsistemas en Nancy Fraser, "Women, Welfare and the Politics of Need Interpretation", Hypatia: A Journal of Feminist Philosophy (en prensa). También véase Barbara. J. Nelson, "Women's Poverty and Women's Citizenship: Some Political Consequences of Economic Marginality", Signs: Journal of Women in Culture and Society, 10:2 (1985); Steven P. Erie, Martin Rein y Barbara Wiget, "Women and the Reagan Revolution: Thermidor for the Social Welfare Economy", en Families, Politics and Public Policies: A Feminist Dialogue on Women and the State, editado por Irene Diamond (New York: Longman, 1983); Diana Pearce, "Women, Work and Welfare: The Feminization of Poverty", en Working Women and Families, editado por Karen Wolf Feinsten (Beverly Hills, CA: Sage Publications, 1979) y "Toil and Trouble: Women Workers and Unemployment Compensation", Signs: Journal of Women in Culture and Society, 10:3 (1985), pp. 439-459; Barbara Ehrenreich y Frances Fox Piven, "The Feminization of Poverty", Dissent, primavera de 1984, pp. 162-170. Para un análisis del carácter sexuado del sistema de seguridad social británico véase Hilary Land, "Who Cares for the Family?" Journal of Social Policy, 7:3 (1978), pp. 157-184. Para Noruega véanse los ensayos en Patriarchy in a Welfare Society, editado por Harriet Holter (Oslo: Universitetsforlaget, 1984). Véanse también los estudios comparativos: Mary Ruggie, The State and Working Women: $A$ Comparative Study of Britain and Sweden (Princeton, N. J.: Princeton University Press, 1984); y Birte Siim, "Women and the Welfare State: Between Private and Public Dependence" (manuscrito inédito). 
Unidos en este siglo. Confirman la existencia de dos zonas distintas de lo privado, la economía oficial y la esfera doméstica, separadas no sólo del discurso público y del Estado, sino también entre sí. Así, las necesidades que lograron escapar a la envoltura económica oficial de lo privado fueron reescritas, con el tiempo, dentro del subsistema "masculino" del Estado social benefactor. Las necesidades que lograron escapar a la envoltura doméstica privada, por otro lado, fueron reescritas dentro del subsistema "femenino". En ambos casos, el movimiento de una necesidad privatizada a una necesidad politizada a una necesidad administrable, no transformó completamente el contenido interpretado. Por el contrario, el supuesto (crecientemente contrafactual) de las "esferas separadas" de una población dividida en jefes o proveedores de familia masculinos y encargadas de niños femeninas se preservó de manera intacta. Este supuesto se incorporó en el marco mismo que rediseñaba las fronteras entre lo público y lo privado, y reubicaba los sitios institucionales de diversas necesidades. Así, las diferencias entre la ubicación de sujetos dentro de los dos subsistemas de bienestar dicen mucho, no sólo sobre el Estado social, sino sobre el carácter de los movimientos sociales que politizaron las necesidades en cuestión. Habla del carácter patriarcal tanto del movimiento Progresista como del sindicalista del siglo $\mathrm{xx}$.

Si bien los dos subsistemas de seguridad social difieren de manera importante en las maneras en que ubican a sus beneficiarios son, no obstante, sụbvariantes de una lógica administrativa común de definición de las necesidades. En ambos subsistemas, las necesidades están descontextualizadas y medidas en términos monetarios. Porque ya sea que ella o él reciban beneficios en efectivo o en especie, la necesidad del beneficiario de la seguridad social se redefine como la correlación de una satisfacción cuantificable que habrá de administrarse burocráticamente. Como resultado, los sujetos de ambos subsistemas se vuelven pasivos. Se les ubica como receptores pasivos de servicios predefinidos, no como copartícipes involucrados en la interpretación de sus necesidades y conformación de sus condiciones de vida.

Este requerimiento de cuantificación, que es a la vez una operación que torna pasivos a los receptores, resulta de la naturaleza del procedimiento administrativo. Las necesidades administrables requieren una variedad de procedimientos de planeación, presupuestos, contabilidad y acreditación. Estos, a su vez, requieren un conocimiento considerable de un tipo específico, operativo. Dicho conocimiento construye a la sociedad desde el punto de vista de sistemas funcionalistas en donde no hay lugar para la política interpretativa. De manera semejante, construye personas que simultáneamente son maximizadoras racionales de la utilidad y objetos causalmente condicionables, predictibles y manipulables, elimi- 
nando así aquellas dimensiones de los agentes que incluyen la construcción y desconstrucción de los significados sociales. En el Estado social, entonces, las necesidades politizadas se integran con los tipos específicos de los aparatos de producción de conocimiento. Pero las necesidades y sus poseedores son redefinidos, como resultado de esta operación..$^{16}$

Además de estas operaciones descontextualizadoras, individualizadoras, generalizadoras y apaciguadoras, la definición administrativa de las necesidades también incluye una operación normalizadora. A medida que las necesidades y sus poseedores se vuelven conmensurables unas con otros, tienden a ser colocados en escalas de normalidad y desviación relativas construidas estadísticamente. Como resultado, el diseño de los servicios tiende a adoptar el carácter de normalización.17 Así, la política familiar, por ejemplo, se sesga en la dirección de la desviación normalizadora; "la familia negra desorganizada [es decir, no nuclear, sin un jefe de familia masculino]" tendría que rehacerse a la imagen de la clase media blanca.

Presiones normalizadoras adicionales provienen de otra fuente más. Dado que las necesidades definidas administrativamente no son ubicables isomórficamente sobre necesidades politizadas, a menudo surgirá una brecha entre la auto-comprensión de los sujetos y la comprensión diseñada para ellos por el Estado social. Esta brecha es un campo para un nuevo giro de intervención administrativa, especialmente en los Estados benefactores más desarrollados (por ejemplo, en el escandinavo). Los sujetos pueden convertirse en receptores de servicios terapéuticos de segundo orden cuya meta es compensar los efectos debilitadores de los servicios de primer orden. ${ }^{18}$ Tales servicios de segundo orden están diseñados, primordialmente, para alentarlos a ajustar las experiencias que han vivido a las exigencias impuestas administrativamente. Cuando esto sucede, la subjetividad interpelada del receptor de hecho se duplica. Ahora, el objeto racional causalmente condicionado, maximizado utili-

16 En Discipline and Punish, op. cit., Michel Foucault ofrece una explicación útil de algunos elementos de los aparatos de producción de conocimiento que contribuyen a las redefiniciones administrativas de las necesidades politizadas. Sin embargo, Foucault soslaya el papel de los movimientos sociales al politizar las necesidades y conflictos de interpretación que surgen entre dichos movimientos y el estado social. Su explicación sugiere, incorrectamente, que los discursos de las políticas emanan sin dirección a partir de instituciones gubernamentales especializadas o cuasi-especializadas; así, pierde el intercambio contestatario entre las interpretaciones hegemónicas y no hegemónicas, limitadas institucionalmente y no limitadas institucionalmente.

17 Véase Foucault, ibid., para una explicación de las dimensiones de los servicios sociales institucionalizados.

18 Jürgen Habermas discute la dimensión terapéutica de los servicios del estado social en Theories des kommunikativen Handelns, Band II, Zur Kritik der funktionalistischen Vernunft, ed cit., pp. 522-547. 
tariamente se vuelve, además, un profundo ser que habrá de ser revelado terapéuticamente. ${ }^{19}$

\section{VIII}

Es claro que la manera que tiene el Estado social de interpretar las necesidades e interpelar a los sujetos se contrapone con las prácticas de los movimientos sociales. Considérese el ejemplo de la "agresión a las esposas". Hasta hace aproximadamente quince años, esta expresión no existía. Este fenómeno se había privatizado en la esfera doméstica y rara vez se le mencionaba en público; no se le consideraba una cuestión política legítima. Entonces, las feministas rompieron el silencio de la privacidad forzada y empezaron a insistir públicamente en las necesidades de las mujeres de proteger su integridad física y vivir en un lugar seguro. Sostenían que esta agresión no era un problema personal y doméstico, sino uno político y sistemático; su etiología podía rastrearse no en los problemas emocionales individuales de hombres y mujeres sino, más bien, en las maneras en que éstos refractaban relaciones sociales profundas de dominación masculina y subordinación femenina. Así, las activistas feministas cuestionaron las fronteras establecidas de lo público y lo privado y politizaron un conjunto de necesidades privadas hasta ese momento. Además, reinterpretaron la experiencia de la agresión y las necesidades que expresaba y engendraba. Más aún, las feministas modificaron los elementos de los medios autorizados de interpretación y comunicación; acuñaron nuevos términos de descripción y análisis e idearon nuevas formas de interpelar a los sujetos femeninos. En su discurso, las mujeres agredidas no eran interpeladas como víctimas individualizadas sino como potenciales activistas feministas, miembros de una colectividad constituida.

Esta intervención discursiva se acompañó de una organización feminista. Las activistas organizaron refugios para mujeres agredidas, lugares seguros, donde, además, se les despertaba la conciencia. La organización de estos lugares no era jerárquica; no había líneas claras entre quienes trabajaban ahf y quienes acudían. Muchas de las consejeras y organizadoras habían sido a su vez agredidas; un porcentaje alto de mujeres que usaron los refugios procedieron, a su vez, a aconsejar a otras mujeres agredidas y se convirtieron en activistas del movimiento.

19 En Discipline and Punish, ed. cit., Michel Foucault discute la tendencia de los procedimientos administrativos con una información cientifica social para el plantea. miento de un ser profundo. En The History of Sexuality, vol. I, An Introduction, ed. cit., discute la ubicación de un ser profundo mediante discursos psiquiátricos terapéuticos. 
Estas mujeres adoptaron nuevas formas de auto-descripción. Mientras que muchas de ellas se habían culpado originalmente a sí mismas y defendian a sus agresores, al creer que merecían el maltrato, en el curso de concientización, la mayoría llegó a rechazar dicha interpretación a favor de una posición politizada que les confirió nuevos modelos de agencia. Además, estas mujeres modificaron sus afiliaciones e identificaciones sociales. Mientras que muchas se habian sentido original y profundamente identificadas con sus agresores, llegaron a afiliarse con otras mujeres.

Esta organización llegó eventualmente a tener un impacto en el terreno social más amplio del discurso público. Para fines de la década de los años setenta, las feministas habían logrado establecer la agresión doméstica, en gran medida, como una cuestión pública legítima. Habían logrado ganarle a este problema un lugar dentro de la agenda política informal. A partir de entonces, las necesidades de las mujeres agredidas estaban lo suficientemente politizadas como para convertirse en candidatos a una satisfacción organizada públicamente. Más aún, en varias municipalidades y localidades, los refugios del movimiento empezaron a recibir fondos de los gobiernos locales. Desde la perspectiva feminista, ello representaba una victoria significativa, pero no se obtuvo sin costo. Junto con los fondos municipales llegó una variedad de nuevas restricciones administrativas, que comprendían desde procedimientos de contabilidad hasta procedimientos de reglamentación, acreditación y profesionalización. Como consecuencia, los refugios con fondos públicos se transformaron al verse sujetos a la lógica de la administración. De manera creciente, llegaron a tener un personal profesional de trabajadoras sociales, muchas de las cuales no habian pasado por la experiencia de la agresión. Asi, una división entre el profesional y el cliente suplantó el continuo más fluido e igualitario de relaciones que caracterizó a los refugios anteriores. Más aún, muchas de las trabajadoras sociales del personal habían sido entrenadas para enmarcar problemas dentro de una perspectiva cuasi-psiquiátrica. Esta perspectiva estructura las prácticas del trabajo social incluso pese a las intenciones del personal individual, muchas de las cuales son feministas comprometidas políticamente. En consecuencia, las prácticas de los refugios con fondos públicos se volvieron más individualizadas y menos politizadas. Las mujeres agredidas tienden ahora a ser consideradas como clientes. Ha aumentado su tendencia psiquiatrizadora. A las mujeres se las interpela de manera creciente como víctimas con personalidades profundas y complicadas; sólo en raras ocasiones se las interpela como activistas feministas potenciales. En general, el lenguaje de juego de la terapia 
ha tendido crecientemente a suplantar el de un despertar de la conciencia. ${ }^{20}$

Al repasar estos acontecimientos no tengo simplemente la intención de denigrar el estado actual de algunos de los refugios para mujeres agredidas. Estos refugios siguen ofreciendo un lugar seguro requerido desesperadamente. Más aún, en los casos en que no se ha obtenido un fondo público, muchos refugios antiguos, al estilo del movimiento inicial, se desplomaron debido a la falta de fondos y al cansancio de las activistas. Así, las feministas se han comprometido, comprensiblemente, a defender los refugios existentes con fondos públicos, frente a recortes presupuestales y una variedad de iniciativas reprivatizadoras.

Aun así, la historia reciente de los refugios para mujeres agredidas arroja luz sobre algunas características importantes de la dinámica de la política de las necesidades en las sociedades capitalistas benefactoras. Ilustra algunas dimensiones de la interacción entre los movimientos sociales de oposición y el Estado social. Muestra que esta interacción incluye un choque entre dos lógicas o génerós sociales distintos de interpretación de las necesidades en conflicto. Los procesos de interpretación de las necesidades en los movimientos sociales son institucionalmente abiertos o sólo institucionalizados informalmente; son relativamente participativos e igualitarios. En los movimientos sociales, entonces, los sujetos se ubican generalmente como copartícipes involucrados en la interpretación de sus necesidades y formación de sus condiciones de vida. Se les interpela de maneras que promueven la identificación colectiva y la adquisición de poder. Los procesos de la interpretación de necesidades en las agencias del Estado social, por otra parte, están institucionalmente limitados, son no participativos y jerárquicos. Los administradores y profesionales definen las necesidades de sus clientes con antelación. Los sujetos son individualizados como "casos" en formas que militan contra la identificación colectiva. Se les pasiviza y quita el poder de la participación con otros en procesos colectivos de interpretación de necesidades. En los términos de Jurgen Habermas, los procesos de interpretación de necesidades característicos de los movimientos sociales son dialógicos, mientras que los del Estado social son monológicos. ${ }^{21}$

En general, entonces, el enfoque del Estado social tiende a sustituir con procesos monológicos, administrativos de definición de necesidades,

20 Para una explicación de la historia de los discursos de mujeres agredidas véase Susan Shechter, Women and Male Violence: The Visions and Struggles of the Battered Women's Movement (Boston: Souths End Press, 1982).

21 Jürgen Habermas, Knowledge and Human Interests, traducción de Jeremy Schapiro (Boston: Beacon Press, 1971), y The Theory of Communicative Action, vol. I, traducción de Thomas McCarthy (Boston: Beacon Press, 1984). 
los procesos dialógicos, participativos de interpretación de necesidades. El manejo administrativo y terapéutico de la satisfacción de necesidades sustituye a la política de la interpretación de necesidades. Cuando se aplica a las necesidades politizadas que ya han ingresado a la arena social, la lógica administrativa del Estado social tiende (o intenta) despolitizar estas necesidades — no repatriándolas a sus enclaves privatizados anteriores, sino, más bien, reformulándolas dentro de una envoltura administrativa. Ciertamente, ésta es una manera de interpretar las necesidades sociales, de enmarcar y ejecutar una política, pero establece limitaciones en la interpretación y tiende (o intenta) parecer no polftica. Tal vez se pueda entender mejor como la oferta de una especie de regateo. Es como si el Estado social le dijera a los movimientos sociales: está bien, has hecho mucho ruido y estamos dispuestos a aceptar en principio que tus necesidades son preocupaciones públicas legítimas, dignas de satisfecerse de una manera organizada públicamente; sin embargo, a cambio de nuestro apoyo, insistimos en preservar para nosotros el derecho de definir tus necesidades y sus satisfacciones en maneras que se conformen a nuestro modus operandi organizativo.

\section{IX}

Ésta es, al menos, una dimensión del eje de cuestionamiento con respecto a las necesidades entre los movimientos sociales y el Estado social. Pero esto no es todo. Hay también otra dimensión de cuestionamiento que incluye resistencia y oposición a los esfuerzos del Estado para definir las necesidades sociales. Dicha resistencia adopta una variedad de formas: puede ser individual o colectiva, cultural o política, formal o informal, organizada o ad hoc.

He aquí algunos ejemplos de resistencia a la lógica administrativa del Estado social en la definición de necesidades que sugiere el rango de posibilidades existente:

1. Los individuos pueden localizar algún espacio para maniobrar dentro del marco administrativo de una agencia gubernamental usando dicho espacio para desplazar y/o modificar las interpretaciones oficiales que la agencia hace de sus necesidades, aun cuando no cuestionen directamente dichas interpretaciones o el contexto administrativo que las enmarca. La historiadora Linda Gordon ha descubierto ejemplos de este tipo de resistencia en los registros de la Sociedad de Massachusetts para la Prevención de la Crueldad hacia los Menores durante la 'Era Progre- 
sista'. ${ }^{22}$ Gordon cita casos en los que mujeres que habían sido golpeadas por sus maridos presentaban quejas alegando maltrato a sus hijos. Al involucrar a los trabajadores sociales en sus situaciones particulares e invocar una necesidad interpretada que se reconocía como legítima y cala dentro de la jurisdicción de la agencia, lograron atraer el interés de los trabajadores sociales hacia una necesidad que no estaba reconocida. En algunos casos, estas mujeres lograron asegurar algún tipo de intervención bajo el rubro de maltrato a los menores, que les ofrecía algún tipo de ayuda en el caso de agresión doméstica. Así, lograron ampliar informalmente la jurisdicción de la agencia para incluir, indirectamente, una necesidad excluida hasta ese momento. Al citar la definición oficial que el Estado social hacía de su necesidad, desplazaban simultáneamente dicha definición y la acercaban a sus propias interpretaciónes.

2. Grupos organizados informalmente pueden desarrollar prácticas y afiliaciones que se contrapongan con la manera que tiene el Estado social de ubicarlos como clientes; pueden utilizar estas prácticas y afiliaciones para alterar los usos y significados de los beneficios que les ofrecen las agencias gubernamentales, sin cuestionarlas abiertamente. La antropóloga Carol Stack ha documentado ejemplos de este tipo de resistencia en su estudio de redes de relación entre los negros pobres, beneficiarios del AFDC en una ciudad de la parte occidental media de los Estados Unidos, a fines de la década de los años sesenta. ${ }^{23}$ Stack narra cómo estas "madres de la seguridad social" se afilian formando redes de familia extensa que abarcan varios hogares físicamente separados. Las redes organizan intercambios o "regalos" en el sentido de Marcel Mauss: comidas preparadas, bonos de alimentos, cocina, compras, abarrotes, lugares para dormir, efectivo (incluyendo salarios y mesadas del AFDC), transportación, ropa, cuidado de niños, e incluso niños. Así, hay una reunión e "intercambio" de beneficios más allá de los límites de la categoría administrativa principal de los programas gubernamentales de ayuda, a saber, "el hogar". En consecuencia, estos clientes circunvienen los procedimientos hacia las familias de los programas de ayuda del Estado social. Al utilizar los beneficios más allá de los límites de un "hogar" alteran los significados definidos por el Estado en el caso de los beneficios, así como en el de las necesidades que intentan satisfacer. Además, cuestionan indirectamente la manera que tiene el Estado social de interpelarlas como madres biológicas pertenecientes a familias nuclea-

22 Linda Gordon, "Feminism and Social Control: The Case of Child Abuse and Neglect" (manuscrito inédito).

${ }_{23}$ Carol B. Stack, All Our Kin: Strategies for Survival in a Black Community (Nueva York: Harper \& Row, 1974). 
res anómalas ya que carecen de jefes de familia masculinos; en efecto, sobreponen esa interpelación con otra, a saber, la de miembros de redes de familia extensa constituidas social y no biológicamente, que cooperan al intentar enfrentarse a los estragos de la pobreza.

3. Los individuos o grupos pueden resistir iniciativas terapéuticas del Estado social, y aceptar por otra parte ayuda material; asimismo pueden rechazar las construcciones terapéuticas de sus vidas y capacidades patrocinadas por el Estado e insistir en convenciones narrativas alternativas y modelos que los constituyan como agentes. La socióloga Prudence Rains ha documentado un ejemplo de este tipo de resistencia en su estudio comparativo de las "carreras morales" de adolescentes embarazadas blancas y de color a fines de la década de los años sesenta. ${ }^{24}$ Rains contrasta la manera en que ambos grupos se relacionaron con las construcciones terapéuticas de sus experiencias en dos marcos instifucionales distintos.

Las jóvenes mujeres blancas, de clase media, eran alojadas en una residencia privada y cara que era una versión moderna y profesional de los antiguos 'hogares para madres solteras'. En dichos lugares se ofrecían además de los cuidados médicos y el apoyo terapéutico el aislamiento que las ${ }_{\supset}$ protegía con una coartada para 'chicas buenas que habian cometido un error'.

El enfoque terapéutico les ofrecía una interpretación de sí mismas como 'seres profundos y complicados' y buscaba hacerles entender el embarazo no sólo como un 'error' del cual el sexo 'premarital' era una causa superficial, sino como un gesto de rechazo a la autoridad de sus padres. Se les advertía que a menos que llegaran a reconocer y comprender estos motivos ocultos y profundos no lograrían evitar 'errores' futuros.

Rains documenta el proceso por medio del cual la mayoría de esas jóvenes, a pesar de su resistencia inicial, llegan a internalizar esta perspectiva y a reinterpretarse a sí mismas en la jerga psiquiátrica. Las nuevas versiones narrativas elaboradas les ofrecian algunas ventajas: ahora podían no sólo superar el pasado sino explicarlo y adquirían además la convicción de ser capaces de actuar de modo distinto en el futuro (p. 94). En apariencia, por tanto, se les ofrecía un modelo de comportamiento que les permitía acrecentar su auto-determinación. Pero el modelo es altamente selectivo, distorsiona dimensiones importantes de su comportamiento, confiesa algunos aspectos y oculta otros. Por ejemplo, sub-

24 Prudence Mors Rains, Becoming an Unwed Mother: A Sociological Account (Chicago: Aldine Atherton, Inc., 1971). En lo que sigue, todas las citas son de esta edición y los números de páginas aparecen en las siguientes citas dentro del texto. Le agradezco a Kathryn Pyne Adelson haberme recomendado el trabajo de Rains. 
estima la sexualidad de las jóvenes al tratar su comportamiento y deseos sexuales como 'manifestaciones epifenoménicas' de "otras necesidades y problemas más profundos y no sexuales" (p. 93).

Además, atenúa la cuestión potencialmente explosiva de la posible coerción experimentada por las adolescentes y clausura cualquier duda referida a la legitimidad de lo que construye como 'sexo premarital', dando por sentado que, al menos para las mujeres, tal sexo es moralmente malo.

El caso de las jóvenes negras presenta un marcado contraste con la relativa facilidad de la 'conversión' de las jóvenes blancas que acabamos de relatar. Estas jóvenes no estaban internadas ni protegidas por el anonimato sino que asistían a una clínica de salud pública y a clases especiales para aquellas que no podían asistir a una escuela pública durante su embarazo. Tenían asimismo sesiones individuales y de grupo con una trabajadora social psiquiátrica. A pesar de que dichas sesiones tenían un objetivo semejante al de las sesiones para las jóvenes blancas, esto es, se les alentaba para que hablaran de sus actitudes y sentimientos y a que buscaran las causas emocionales profundas de sus embarazos, el enfoque terapéutico tuvo mucho menos éxito en este caso.

Las jóvenes negras manifestaron mayor resistencia para aceptar los términos del discurso psiquiátrico y el juego de lenguaje de pregunta y respuesta empleado en las sesiones. Expresaron disgusto ante la postura no involucrada y de neutralidad moral de la trabajadora social y resentimiento ante sus preguntas entrometidas y abiertamente personales. Dado que ellas no podían dirigirle el mismo tipo de preguntas, concluian que esa clase de interrogatorio personal debería quedar reservado a amigos cercanos o íntimos bajo condiciones de reciprocidad.

Las jóvenes negras del estudio de Rains desarrollaron un amplio repertorio de estrategias de resistencia ante las construcciones terapéuticas que intentaban redefinir sus vidas. Percibían de manera mucho más clara que las jóvenes blancas el subtexto de poder que subyacía a las interacciones con la trabajadora social psiquiátrica, así como las pretensiones 'normalizadoras' de su intervención. De hecho, las jóvenes negras defendían concepciones culturales no hegemónicas de la sexualidad femenina adolescente, la maternidad, la solidaridad y la auto-determinación en contra de los esfuerzos del Estado social para inculcarles normas blancas, de clase media, de individualidad y afectividad. De manera semejante, estas jóvenes rechazaban los intentos de las trabajadoras sociales de inducirlas a 'reescribirse' o reentenderse a sí mismas como seres profundos y complicados, mientras que, por otra parte, aceptaban sin conflictos los servicios médicos que se les proporcionaban. Así, podían hacer uso de aquellos aspectos del programa de ayuda oficial que con- 
sideraban adecuado a sus necesidades, tal y como éstas èan interpretadas por ellas mismas e ignoraban o hacían a un lado lo demás.

4. Además de las formas informales, ad hoc, estratégicas y/o culturales de resistencia al estado social, hay también formas organizadas, explicitamente políticas. Los clientes de los programas de seguridad social pueden reunirse como clientes para cuestionar las definiciones administrativas de las necesidades y las interpelaciones a los sujetos. Pueden tomar las identidades pasivizantes, normalizantes e individualizantes o familiarizantes diseñadas para ellos por el estado social y transformarlo en una identidad que les ofrece una base para la acción política colectiva. Frances Fox Piven y Richard Cloward han documentado un ejemplo de este tipo de resistencia en su explicación del proceso mediante el cual los recipendarios del AFDC organizaron el movimiento de los derechos a la seguridad social en la década de los años sesenta. ${ }^{25}$ Pese a las tendencias atomizadadoras y despolitizadoras e intenciones de la administración AFDC, estas mujeres llegaron a reunirse de hecho en las salas de espera de los lugares de seguridad social. Así, como resultado de su participación como clientes dentro del sistema de seguridad social, llegaron a actuar juntas en términos de problemas comunes generados por las prácticas de la seguridad social. En otras palabras, las mismas prácticas sociales que generaron sus malestares generaron simultáneamente condiciones para la posibilidad de una organización colectiva para combatirlas. En las palabras de Piven, "la estructura del Estado benefactor las ha ayudado a crear nuevas solidaridades y generar las cuestiones políticas que continúan uniéndolas y encendiéndolas." ${ }^{26}$

Un ejemplo más reciente de este tipo de resistencia se refiere a los clientes de las viviendas populares (propiedad del Estado o subsidiadas públicamente). Estos clientes, asimismo, son de sexo femenino en su mayoria; de hecho, hay una traslapación sustancial entre los beneficiarios del AFDC y los ocupantes de las viviendas populares. Como los beneficiarios del AFDC, los residentes de las viviendas populares se han reunido en virtud de su participación dentro del sistema de seguridad social. En su caso, la proximidad generada por el servicio social es más durable; estas mujeres y niños viven juntos. Usan elevadores inseguros y suben muchas escaleras juntos cuando los elevadores no sirven. Se enfrentan a calefacciones inadecuadas, roedores y otras condiciones inseguras y desmoralizantes juntos. Así, no sorprende que durante los úl-

25 Frances Fox Piven y Richard A. Cloward, Regulating the Poor: The Functions of Public Welfare (Nueva York: Vintage Books, 1971), pp. 285-340. Véase también Guida West, The National Welfare Rights Movement: The Social Protest of Poor Women (Nueva York: Praeger Publishers, 1981).

26 Frances Fox Piven, "Women and the State: Ideology, Power and the Welfare State", Socialist Review, núm. 74 (marzo-abril de 1984), pp: 11-19. 
timos años hayan formado organizaciones de arrendatarios para presionar a los gobiernos municipales a que hagan algo en relación con el crimen, la seguridad, reparaciones, incrementos en la renta y cuestiones semejantes. Algunas de estas organizaciones han desarrollado tácticas y estrategias crecientemente sofisticadas. Han formado coaliciones multiraciales, multi-culturales, a través de toda la ciudad y se han embarcado en formas imaginativas de protesta pública. Por ejemplo, en Chicago, más de mil activistas residentes de viviendas populares se reunieron recientemente en una conferencia sobre "Las mujeres y un techo seguro" para intercambiar información y afianzar contactos. ${ }^{27}$ Después de la conferencia, varios miembros del grupo se reunieron el día de la madre para protestar contra los recortes en los fondos para viviendas a personas de escasos recursos para subsidiar bienes raíces lujosos y caros. Además, algunos arrendatarios dentro de la coalición lograron recientemente, después de años de organización, ganar una "administración coarrendataria"; asumirán la responsabilidad, en cooperación con el municipio, de administrar su propio complejo habitacional.

Estos ejemplos demuestran que, bajo ciertas condiciones, los clientes de la seguridad social pueden desplazar el significado y carácter de la interpelación que se les impone. Pueden transformar la posición de cliente con un estigma que denota dependencia, atomización y debilitación, en una identidad política, la identidad de una colectividad constituida que denota activismo, solidaridad y adquisición de poder. $\mathrm{Al}$ hacerlo, tales clientes cuestionan simultáneamente las definiciones administrativas de su necesidades y la lógica anti-participativa y jerárquica de la definición administrativa de necesidades.

\section{$\mathbf{X}$}

¿Cómo debemos evaluar la elevación del habla de "necesidades al status de una expresión política importante en las sociedades capitalista benefactoras? ¿Cómo debemos evaluar las oportunidades o limitaciones que estas expresiones plantean a los movimientos interesados en una transformación social emancipatoria?

Al evaluar el habla sobre necesidades, es crucial tener en mente que no nos ocupamos de un solo discurso univalente, sino más bien, con un campo de discursos en competencia. Hablar de necesidades en las sociedades capitalistas benefactoras es por definición plural y contestatario.

27 La conferencia "Las mujeres y un techo seguro" fue organizada por la Universidad de Illinais dentro del Programa de Estudios de Mujeres de Chicago y tuvo lugar en la Universidad de Illinois en Chicago, los dias 25 y 26 de abril de 1986. 
Hemos identificado tres tendencias distintas en el habla sobre necesidades; cada una de ellas deriva su forma y sentido de su relación dialógica y polémica con las demás. En primer lugar, hay discursos que tienen como meta politizar necesidades previamente privatizadas y que son iniciados por personas subordinadas o grupos embarcados en diseñar nuevas identidades sociales de oposición. En segundo lugar, hay discurso cuya meta es reprivatizar necesidades recientemente politizadas y defender la división social establecida entre discursos al articular interpretaciones enraizadas en necesidades que podían darse por dadas anteriormente. $\mathrm{Y}$, en tercer lugar, hay discursos que traducen necesidades politizadas a necesidades administrables, incluyendo tanto discursos terapéuticos de trabajadoras sociales profesionales y discursos de sistemas funcionalistas de plànificadores, expertos en políticas y científicos sociales de la corriente dominante. Sin duda, hay otras tendencias en los discursos sobre las necesidades en las sociedades capitalistas benefactoras.

Al reconocer el carácter plural y contestatorio de esta habla contemporánea sobre necesidades, nos percatamos de lo inadecuado de las estrategias evaluativas que pretenden resolver el problema aceptando o rechazando el discurso sobre necesidades in toto. Tanto la historia de Arendt como la del progreso mencionadas anteriormente, son de este tipo. La narrativa de Arendt asimila toda habla sobre necesidades al discurso administrativo y rechaza así las expresiones de necesidades sin distinciones. La historia del progreso, por otro lado, identifica el discurso administrativo con un discurso orientado hacia la justicia, extraestatista, y así acepta las expresiones sobre necesidades a-criticamente. Así, ninguna de estas dos estrategias evaluativas resulta adecuada para la complejidad y multivalencia de esta habla actual sobre necesidades en la cultura politica capitalista benefactora contemporánea.

Un enfoque más adecuado y matizado debe ser capaz de distinguir y evaluar diferencialmente las diversas tendencias en competencia de estos discursos contemporáneos sobre necesidades. ¿Pero cómo emprender esta tarea de la manera más fructífera? Al optar por una concepción historizada de la necesidad, ya hemos descartado de hecho los enfoques naturalistas que suponen que buscamos aquel discurso de las necesidades que penetre la realidad en la médula al reflejar fielmente la verdadera naturaleza de las necesidades tal y como son en realidad, independientemente de cualquier mediación culturalmente discursiva. De manera semejante, al optar por concepciones historizadas, discursivas, de lo público y lo privado, hemos descartado de hecho los enfoques esencialistas que presuponen que algunas cuestiones simplemente son intrínsecamente privadas y otras simplemente son intrínsecamente pú- 
blicas, independientemente de toda mediación cultural-discursiva. Entonces ¿con cuáles enfoques no naturalistas, no esencialistas, podemos contar?

Considérese la posibilidad de evaluar los discursos de necesidades con respecto a un modelo de justicia distributiva. Usualmente, dichos modelos se aplican para evaluar la justicia de diversos patrones de distribución de "bienes" diversos. Por ejemplo, podría plantearse la siguiente pregunta: ¿el cuidado de la salud está distribuido con justicia cuando se reparte sobre la base de la capacidad para pagar por él? Obviamente, tales preguntas son extremadamente importantes. De hecho, ninguna teoría política de las sociedades capitalistas benefactoras puede darse el lujo de ignorarlas. Sin embargo, este uso del paradigma de la justicia distributiva es también bastante limitante. Es la contraparte normativa de la posición del sentido común de las políticas de la necesidad discutidas anteriormente $y$, así, elude algunas importantes preguntas politicas. En primer lugar, da por hecho que todos sabemos y concordamos en cuanto a lo que constituye- un buen cuidado de la salud, y que la interpretación de los "bienes", cuya distribución está en juego, no está ella misma en juego. En segundo lugar, presupone que no tiene gran importancia politica quién defina de manera autoritaria los bienes en cuestión, ya sean doctores, enfermeras, administradores, políticos o legos que nos dirán en qué consiste el cuidado de la salud. En tercer lugar, supone que los recursos discursivos autorizados disponibles para hablar de la salud son adecuados y que no están sesgados a favor de los intereses, perspectivas y comprensiones culturales de individuos y grupos dominantes. Finalmente, el paradigma estándar de la justicia distributiva supone que no es especialmente significativo el lugar o los medios a través de los cuales los procesos de comunicación y las relaciones de las necesidades del cuidado de la salud y sus servicios se interpretan con autoridad, ya sea, por ejemplo, que la salud sea interpretada en instituciones estatales, profesionales, de la comunidad, o de algún movimiento, y si los procesos y relaciones de comunicación involucrados son jerárquicos o igualitarios, participativos o no, monológicos o dialógicos.

Si queremos un modelo de justicia distributiva que no soslaye preguntas normativo-políticas tan importantes, necesitaremos dar un paso atrás. Necesitaremos congelar la aplicación de criterios de justicia a patrones de distribución de "bienes" hasta que hayamos considerado un punto distributivo lógicamente anterior: ¿qué tan justa es la distribución de acceso y control sobre los medios de interpretación y comunicación en términos de los cuales se definen con autoridad los "bienes"? ¿Quién participa en la construcción de los significados sociales autori- 
zados de los bienes y/o necesidades? ¿Quién queda excluido de la participación? ¿Los intereses, perspectivas y experiencias de quiénes pueden encontrar una expresión fácil en términos de los elementos hegemónicos de los medios de interpretación y comunicación? ¿Los intereses, perspectivas y experiencias de quienes quedan descalificados, son distorsionados o callados cuando se expresan en términos de tales elementos hegemónicos? ¿Hasta qué punto y de qué manera la organización y carácter de los MIC reflejan patrones de dominación y subordinación? ¿Hasta qué punto y de qué manera estimulan o impiden la posibilidad de que miembros de deferentes grupos socio-culturales participen a la par unos con otros en los procesos de interpelación y comunicación? Es claro que estas preguntas pertenecen al ámbito de la justicia distributiva. Pero el "bien" cuya distribución está en juego es de segundo orden o un "meta-bien". Es el acceso y control sobre los recursos discursivos mediante los cuales se construyen los significados sociales de todos los bienes y necesidades de primer orden. Estas preguntas, así, son preguntas de lo que quisiera llamar la justicia discursiva distributiva. ${ }^{28}$

28 Mis ideas sobre la noción de justicia discursiva distributiva han recibido la influencia de diversos escritores, especialmente de Michael Walzer, Jürgen Habermas y Jean-François Lyotard. Estoy convencida de que los argumentos de Walzer en el sentido de que los paradigmas estándares de justicia distributiva están equivocados en la medida en que no atienden al hecho de que los bienes siempre son necesariamente bienes interpretados; y las cuestiones de justicia distributiva no pueden dirimirse sin atender a los "significados sociales" de los bienes en cuestión. Sin embargo, concuerdo con el supuesto (no argumentado) de Walzer de que uno no debe atender al carácter de los procesos comunicativos mediante los cuales llegan a existir los significados sociales. Más aún, rechazo los supuestos de Walzer en el sentido de que hay un solo significado social uńfvoco e incuestionado y que los significados sociales hegemónicos no pueden estar ellos mismos sujetos a criticas en términos de consideraciones de justicia de altos ordenes. Para llegar a estas consideraciones de alto orden propongo la noción de justicia discursiva distributiva. Véase Michael Walzer, Spheres of Justice: A Defense of Pluralism and Equality (Nueva York: Basic Books, 1983).

Esta noción tiene ciertas afinidades con la "ética de discurso" de Jürgen Habermas. Concuerdo con Habermas en el sentido de que es importante ver por debajo de la superficie de consensos sociales aparentes a fin de considerar si los procesos comunicativos mediante los cuales llegaron a existir son o no justos. Sin embargo, rechazo la meta de Habermas - desde mi punto de vista implausible e innecesaria- de fundamentar tal ética del discurso en una "teoria de la pragmática universal" trascendental o cuasi-trascendental o en una "teoría de la evolución". Véase Jürgen Habermas, Communication and the Evolution of Society, traduccion de Thomas McCarhty (Boston: Beacon Press, 1979) y Moralbewusstsein und kommunikatives Handeln (Frankfurt: Suhrkamp Verlag, 1983). Véase también Nancy Fraser, "Toward a Discourse Ethic of Solidarity", ed. cit., y "What's Critical About Critical Theory? The Case of Habermas and Gender", ed. cit.

Finalmente, mi concepción de la justicia discursiva distributiva tiene la intención de ocuparse del tipo de situación que Jean-François Lyotard ha discutido bajo el término de "el diferendo", a saber, una forma aguda de daño que se perpetra cuando un conflicto entre dos partidos se "regula" en la expresión discursiva de una de ellas, "mientras que la injusticia sufrida por la otra parte no queda significada en 
En algún momento, ciertamente valdría la pena intentar desarrollar un modelo de justicia discursiva distributiva que pudiera utilizarse para analizar y evaluar los diversos discursos de necesidades en competencia dentro de las sociedades capitalistas benefactoras. Tal modelo tendría que plantear una serie de preguntas que tiene que ver, simultáneamente, con la extensión de la participación y el carácter de las relaciones de comunicación entre los participantes. Por ejemplo: ¿̨cuán inclusivos o exclusivos son los diversos discursos sobre necesidades en competencia y qué tipos de exclusión operan? ¿Hasta qué punto los diversos discursos sobre necesidades ubican a algunas personas como sujetos y a otras como objetos? ¿Hasta qué punto privilegian elementos de los medios de interpretación y comunicación que no son igualmente accesibles a todos los interlocutores potenciales? ¿Hasta qué punto se estructuran los diversos discursos de necesidades en competencia de manera que estimulen la participación de miembros de algunos grupos socio-culturales e impidan al mismo tiempo la participación de otros? ¿Qué tan recíprocas, igualitarias y dialógicas son las relaciones entre los participantes en los diversos discursos? ¿Todos los participantes tienen igual acceso a todas las posiciones dentro de tales discursos? ¿Todos participan a la par unos con otros?

No puedo desarrollar en este momento un modelo tal de justicia discursiva distributiva. $A$ fortiori, no puedo aplicar ahora un modelo tal para evaluar los méritos de las tres tendencias más importantes en los discursos de necesidades identificadas anteriormente. Pero aventuraré una predicción: dado tal modelo, los discursos de los movimientos sociales sobre necesidades serán mejores que los discursos del Estado social o los reprivatizadores.

Si efectivamente es cierto que los discursos de los movimientos sociales sobre las necesidades representan nuestra mejor esperanza hacia una transformación progresiva y emancipatoria de la cultura política capitalista benefactora, entonces ¿̨cómo debemos evaluar sus prospectos de éxito dentro de la configuración contestataria contemporánea? Es claro que los movimientos sociales de oposición se encuentran luchando en dos frentes a la vez. Por un lado, deben cuestionar a los privatizadores y reprivatizadores a medida que luchan por establecer y mantener el carácter político, público y legítimo de sus necesidades. Por otro lado, y al mismo tiempo, los movimientos sociales deben cuestionar la lógica ad-

dicha expresión". Véase Lyotard, "The Differend, the Referent, and the Proper Name", traducción de Georges Van Den Abbeele, Diacritics (otoño de 1984), pp. 4-14. Para una discusión crítica de Lyotard véase Nancy Fraser y Linda Nicholson, "Social Criticism Without Philosophy: An Encounter Between Feminism and Postmodernism", en The Institution of Philosophy, editado por Avner Cohen y Marcelo Dascal (Totowa, N. J.: Rowman and Allanheld, en prensa). 
ministrativa del Estado social a medida que luchan por el poder para interpretar las necesidades de sus miembros e instituir relaciones democráticas, dialógicas y que les confieran poder. La persecución simultánea de estos dos tipos de lucha no sería un asunto sencillo, aun en las mejores circunstancias, y hoy en día las circunstancias difícilmente son las mejores.

De cualquier modo, dejando de lado consideraciones de optimismo o pesimismo, vale la pena formular, si no resolver, los puntos políticoteóricos centrales a los que se enfrentan los movimientos sociales de oposición hoy en día: ¿cómo pueden asegurarse las capacidades interpretativas y comunicativas que se desarrollan dentro de tales movimientos frente a las fuerzas de reprivatización y administración? ¿Cómo puede darse una forma no efímera, institucional a las relaciones comunicativas, dialógicas, democráticas y participativas que surgen dentro de tales movimientos? ¿Cómo pueden contribuir los movimientos de oposición a la construcción de un nuevo orden social cuya finalidad sea estimular tales relaciones como una prioridad por encima de los imperativos patriarcales-capitalistas que actualmente estructuran las instituciones económicas oficiales, doméstico-familiares y administrativo-estatales?

Traducción DE Adriana Sandoval 